\title{
A Cross-sectional Survey Using Clinical Vignettes to Examine Overdose Risk Assessment and Willingness to Prescribe Naloxone
}

\author{
J. Deanna Wilson, $M D, M P H^{1,2,3}$, Justin Berk, $M D, M P H, M B A^{1,2}$, Pamela Matson, $P h D, M P H^{1}$, \\ Natalie Spicyn, MD, MHS ${ }^{1,2}$, Anika Alvanzo, MD, MHS ${ }^{2}$, Hoover Adger, MD, MPH, MBA ${ }^{7}$, and \\ Leonard Feldman, $\mathrm{MD}^{2}$
}

'Department of Pediatrics, Division of General Pediatrics and Adolescent Medicine, Johns Hopkins University School of Medicine, Baltimore, MD,
USA; '2Department of Internal Medicine, Division of General Internal Medicine, Johns Hopkins University School of Medicine, Baltimore, MD, USA;
${ }^{3}$ Divisions of General Internal Medicine, University of Pittsburgh School of Medicine, Pittsburgh, PA, USA.

KEY WORDS: clinical vignette; medical education-systems based practice; substance abuse; vulnerable populations.

J Gen Intern Med 34(4):507-9

DOI: $10.1007 / \mathrm{s} 11606-018-4733-y$

(c) Society of General Internal Medicine 2018

\section{INTRODUCTION}

The number of opioid-related overdose deaths has increased concurrently with rising rates of opioid use nationally. ${ }^{1}$ Clinical encounters offer an opportunity to provide high-risk patients with targeted interventions, ${ }^{2}$ yet clinicians routinely miss the opportunity to deliver risk reduction counseling and naloxone to appropriate patients ${ }^{3}$ due, in part, to knowledge gaps. ${ }^{4,5}$

To better identify physician education targets, we examined how internal medicine trainees' beliefs influence willingness to prescribe naloxone, how residents assess risk of opioidrelated overdose, and concordance between risk assessment and naloxone prescription.

\section{METHODS}

The study occurred at an academic medical center in Baltimore, MD, with high rates of opioid use and overdose. IRB deemed our study exempt. We surveyed internal medicine residents and collected information on beliefs and behaviors based on seven clinical vignettes. Each vignette provided patient-specific information including age, medical comorbidities, type, and quantity of opioids, and if opioids were chronically or acutely prescribed. Vignettes incorporated a range of overdose risk factors discussed in the literature: opioid dose > 50-100 morphine milligram equivalents (MME) per day confer a moderate risk, dose $>100 \mathrm{MME} /$ day confer a high risk; presence of co-occurring substance use and history of previous overdose both increase risk of overdose compared to those without similar risk factors. ${ }^{1}$ We asked residents the likelihood of overdose risk on a four-point scale (not likely, low, medium, or high) and if they would prescribe naloxone.

We completed bivariate analyses looking at relationship of provider characteristics, history of having prescribed

Published online November 7, 2018 naloxone, and willingness to prescribe in the future using STATA (v.15.0, StataCorp). To analyze clinical vignettes, we collapsed risk assessment as determined by the residents into two categories of overdose likelihood: not likely/low and moderate/high. We defined discordant prescribing as occurring when residents rated patients as not likely or low risk of opioid overdose, but still prescribed naloxone and when residents rated patients as moderate to high risk but, did not prescribe naloxone.

\section{RESULTS}

The survey response rate was $68 \%(N=97)$, divided evenly among all training years. Beliefs increasing the willingness to prescribe naloxone included positive attitudes on addiction education and believing naloxone is effective in reducing overdose (Table 1). Physician demographic factors were not associated with willingness to prescribe naloxone including age (OR 0.83; 95\%CI 0.65, 1.07); gender (OR 0.68; 95\%CI $0.20,2.26)$; race (OR 0.28 ; $95 \% \mathrm{CI} 0.46,3.62)$; or year of training (OR 0.74, 95\% CI 0.38, 1.53). Having prescribed naloxone in the past did not increase the residents' likelihood of prescribing naloxone in these vignettes (OR 0.85 ; 95\% CI $0.16,4.39)$.

Residents correctly identified those using illicit opioids at moderate or high risk of overdose; however, they consistently underestimated overdose risk even in those taking high doses of opioids (Table 2).

Willingness to prescribe naloxone was discordant from the risk assessment. Among those viewed by residents as being at moderate to high risk of overdose, residents prescribed naloxone to only about $50 \%$ of patients prescribed opioids compared to $83 \%$ misusing opioids and $93 \%$ who injected drugs.

\section{DISCUSSION}

Physicians-in-training correctly identified patients at the highest risk for opioid-related overdose; however, they underestimated risk for overdose among those receiving prescription opioids. If this holds true for their clinical encounters, 
Table 1 Beliefs Associated with Odds of Being Willing to Prescribe Naloxone to Eligible Patients (N-97)

\begin{tabular}{lll}
\hline \hline Statements* & $\begin{array}{l}\text { Odds ratio if somewhat or } \\
\text { strongly agree with } \\
\text { statement (95\% } \\
\text { confidence interval) }\end{array}$ & $\begin{array}{l}\boldsymbol{p} \\
\text { value }\end{array}$ \\
\hline $\begin{array}{l}\text { Naloxone will cause people to } \\
\text { use more drugs }\end{array}$ & $0.19(0.04,0.97)$ & 0.05 \\
$\begin{array}{l}\text { Naloxone enables illegal drug } \\
\text { use }\end{array}$ & $2.06(0.24,17.49)$ & 0.51 \\
$\begin{array}{l}\text { Residents should receive } \\
\text { education about addiction }\end{array}$ & $16.22(2.59,101.45)$ & $<$ \\
$\begin{array}{l}\text { Residents should learn how to } \\
\text { counsel patients to reduce their } \\
\text { overdose risk }\end{array}$ & $2.79(1.28,6.07)$ & 0.01 \\
$\begin{array}{l}\text { Naloxone use will cause } \\
\text { people to use drugs in riskier }\end{array}$ & $0.35(0.09,1.34)$ & 0.01 \\
$\begin{array}{l}\text { ways } \\
\text { Naloxone is an effective } \\
\text { strategy to reduce overdose }\end{array}$ & $38.40(7.70,191.52)$ & 0.12 \\
$\begin{array}{l}\text { Residents have a responsibility } \\
\text { to educate patients }\end{array}$ & $1.43(0.16,12.52)$ & $<$ \\
\hline
\end{tabular}

* Respondents were asked if how much they agreed with each statement on a 4-point Likert scale from 1, strongly disagree, to 4, strongly agree. For analysis, we collapsed somewhat disagree and strongly disagree into one category (serving as reference category) and somewhat agree and strongly agree into another category.

they may routinely underestimate the risk of overdose and may fail to deliver overdose prevention to patients at risk.

It is disappointing that our residents, despite having positive beliefs about naloxone, did not always prescribe naloxone to patients they identified as having a moderate to high risk for overdose. They may be worried about stigmatizing patients or alienating them by discussing overdose prevention. ${ }^{6}$ These concerns may be more pronounced for elderly patients or those with opioid prescriptions. Residents may also assume elderly patients use less opioids overall or use them in less risky ways than younger patients.

Study limitations include being small and from a singleinstitution, limiting its generalizability. Moreover, clinical decisions using vignettes may not generalize to actual clinical decision-making. It does, however, provide some important insight and suggests future directions to explore biases informing overdose risk assessment and naloxone prescribing patterns.

Even when residents identify patients at risk of overdose, they often fail to prescribe naloxone. Systems interventions are needed to remind physicians about all patients for whom a naloxone prescription and appropriate counseling are indicated. Additional research should explore the reasons behind discordant prescribing patterns and help physicians better link risk assessment to naloxone prescription.

Acknowledgements: This work was delivered as a presentation in November 2016 at the Association for Medical Education and Research in Substance Abuse Meeting.

Corresponding Author: J. Deanna Wilson, MD, MPH; Divisions of General Internal Medicine, University of Pittsburgh School of Medicine, 200 Meyran Avenue, Suite 200, Office 213, Pittsburgh, PA 15213, USA (e-mail: wilsonjd@pitt.edu).

Funding Information This work was supported by Johns Hopkins University Scholars' Fund. Dr. Wilson was supported by HRSA LEAH (T71MC08054) and NIH (T32HD052459-07). Dr. Matson was supported by NIDA K01DA035387.

\section{Compliance with Ethical Standards:}

Conflict of Interest: The authors do not have conflicts of interest to disclose.

Table 2 Overdose Risk Assessment and Willingness to Prescribe Naloxone by Residents for a Series of Clinical Vignettes

\begin{tabular}{|c|c|c|c|c|}
\hline \multirow[t]{2}{*}{ Summarized clinical vignettes } & \multirow[t]{2}{*}{$\begin{array}{l}\text { Assumed risk } \\
\text { category* }\end{array}$} & \multicolumn{2}{|c|}{$\begin{array}{l}\text { Percentage endorsing risk } \\
\text { of opioid-related overdose }\end{array}$} & \multirow{2}{*}{$\begin{array}{l}\text { Percentage willing to } \\
\text { prescribe naloxone to } \\
\text { patient }\end{array}$} \\
\hline & & $\begin{array}{l}\text { Not likely } \\
\text { to low }\end{array}$ & $\begin{array}{l}\text { Medium to } \\
\text { high }\end{array}$ & \\
\hline $\begin{array}{l}\text { Correctly identified those at most risk for opioid-related overdose } \\
\text { Young man endorsing prescription opioid misuse (currently taking } \\
50 \mathrm{mg} \text { morphine equivalents/day). No history of overdose or } \\
\text { injection drug use }\end{array}$ & Medium-high & 5 & 95 & 68 \\
\hline $\begin{array}{l}\text { Middle age man with injection opioid use w/ overdose } 1 \text { month } \\
\text { prior } \\
\text { Underestimated risks in patients prescribed opioids }\end{array}$ & Medium-high & 5 & 95 & 90 \\
\hline $\begin{array}{l}\text { Young man w/ sickle cell disease presenting with acute on chronic } \\
\text { pain on baseline of } 90 \mathrm{mg} \text { MME/day with } 15 \mathrm{MME} 1-2 \times / \text { day }\end{array}$ & Medium-high & 50 & 50 & 44 \\
\hline $\begin{array}{l}\text { Elderly female prescribed } 100 \mathrm{mg} \text { morphine equivalents (MME)/ } \\
\text { day chronically }\end{array}$ & Medium-high & 60 & 40 & 25 \\
\hline Varied risk assessment in patients receiving low-dose opioids chroni & ally or acutely & & & \\
\hline $\begin{array}{l}\text { Middle age man } \mathrm{w} / \text { femur fracture } \mathrm{c} / \mathrm{b} \text { alcohol withdrawal. } \\
\text { Discharged on } 7.5 \mathrm{MME} \text { every } 4 \mathrm{~h}\end{array}$ & Medium-high & 21 & 79 & 52 \\
\hline $\begin{array}{l}\text { Elderly woman prescribed } 5 \mathrm{MME} \text { every } 8 \mathrm{~h} \text { as needed for knee } \\
\text { pain }\end{array}$ & Low & 63 & 37 & 25 \\
\hline Young woman with a history of pancreatitis on $15 \mathrm{MME}$ every $4 \mathrm{~h}$ & Medium-high & 36 & 64 & 34 \\
\hline
\end{tabular}

MME morphine milligram equivalents. *Risk factors for risk based on opioid risk (low risk is $<50$ MME/day, medium risk is $\geq 50-100$ MME/day, $>100$ $M M E /$ day is high risk); presence of substance use disorder (elevated (medium-high) risk if positive), history of opioid overdose (elevated (high) risk if positive) 


\section{REFERENCES}

1. Volkow ND and McLellan AT. Opioid abuse in chronic-painmisconceptions and mitigation strategies. NEJM. 2016;374:1253-63.

2. Coffin PO, Behar E, Rowe C, et al. Nonrandomized Intervention Study of Naloxone Coprescription for Primary Care Patients Receiving Long-Term Opioid Therapy for Pain. Ann Intern Med. 2016;165(4):245. doi:https:// doi.org/10.7326/M15-2771.

3. Starrels JL, Becker WC, Weiner MG, Li X, Heo M, Turner BJ. Low use of opioid risk reduction strategies in primary care even for high risk patients with chronic pain. J Gen Intern Med. 2011;26(9):958-964. doi:https://doi. org/10.1007/s11606-011-1648-2.
4. Binswanger IA, Koester S, Mueller SR, Gardner EM, Goddard K, Glanz JM. Overdose Education and Naloxone for Patients Prescribed Opioids in Primary Care: A Qualitative Study of Primary Care Staff. J Gen Intern Med. 2015;30(12): 1837-1844. doi:https://doi.org/10.1007/s11606-015-33943.

5. Wilson JD, Spicyn N, Matson $\mathbf{P}$, Alvanzo A, Feldman L. Internal medicine resident knowledge, attitudes, and barriers to naloxone prescription in hospital and clinic settings. Subst Abus. 2016;37(3):480-487. doi:https://doi.org/10.1080/08897077.2016.1142921.

6. Haug NA, Bielenberg J, Linder SH, Lembke A. Assessment of provider attitudes toward \#naloxone on Twitter. Subst Abus. 2016;37(1):35-41. doi:https://doi.org/10.1080/08897077.2015.1129390. 